\title{
Histopathology of conducting system in left anterior hemiblock
}

\author{
Lino Rossi ${ }^{1}$ \\ From 2nd Institute of Pathology, the University of Milan, Milan, Italy
}

In 8 cases of left anterior hemiblock, combined with right bundle-branch block in 7 , serial sections of the conducting system of the heart were examined histologically.

In all cases there were pathological changes in the left bundle-branch but the anterior part of it was predominantly affected in only 2 cases. Acute changes were found in 6 cases of early myocardial infarction, and fibrosis in 2 cases of chronic heart disease. Reversible lesions may have a pathogenetic role in acute hemiblocks. The right bundle-branch was disrupted by fibrosis in 6 of the 7 cases with right bundle-branch block, and minor changes in the $A V$ node were observed in 1.

The widespread damage to the left bundle-branch in the majority of the present cases does not seem to be consistent with the limited clinicopathological correlation implied by the terms anterior fascicular block or hemiblock. Other cardiac lesions within the left bundle-branch and outside it may contribute to this electrocardiographic pattern.

The use of the term 'left hemiblock' is based on the concept that there is anatomical and functional dichotomy of the left bundle-branch into an anterior and a posterior fascicle, and on the inferred trifascicular character of the conducting system (Rosenbaum, Elizari, and Lazzari, 1968; Rosenbaum et al., 1970). This assumption that isolated block of one division of the left bundle-branch may occur alone or in combination with right bundlebranch block made it possible to give quick and easy answers to debated questions about intraventricular conduction defects and axis deviation (Pryor and Blount, 1966; Rosenbaum, 1970). This explains why the idea and the clear-cut terminology of hemiblock or fascicular block, implying disease of a discrete segment of the left bundle-branch system, have become popular among cardiologists.

This view was not shared by histopathologists, who criticized the original descriptions of hemiblocks on both anatomical and pathological grounds (Blondeau and Lenègre, 1970; Rossi, 1970, 1971; J. Lenègre, 1971, personal communication; Demoulin and Kulbertus, 1972). Sugiura et al. (1969) and Harris, Siew, and Lev (1969) appeared to accept the morphological basis of the concept of hemiblock,

Received 22 December 1975.

'Present address: Via Annunciata 23/4, 20121 Milan, Italy. but later Lev has become critical of it (Hecht et al., 1973).

Experimental studies have been reported in which the alleged twin ramifications of the left bundlebranch were separately cut (Medrano et al., 1975), but in these studies the resulting lesions were not examined histologically, so that no light was shed on the actual morphological basis of the 'hemiblocks' which were produced (Rossi, 1975).

Anatomical, physiological, and pathological evidence casts doubt on the validity of the hemiblock concept. Anatomically, a definite subdivision of the left bundle-branch into two fascicles is uncommon in man. In most hearts the left bundle-branch is known to fan out into three distal strands, anterior, middle, and posterior (Rossi, 1971, 1974; Hecht et al., 1973), freely anastomosing with one another, making it difficult to discern any anatomical and clear functional separation (Blondeau and Lenègre, 1970). Physiologically, left ventricular activation in the human heart starts simultaneously in three septo-paraseptal areas (Durrer et al., 1970), suggesting three rather than two pathways of impulse distribution. Clinicophysiological studies by Kulbertus (1972) also suggested that it might be possible to distinguish conduction disturbances in the mid-septal group of left bundle-branch fibres. Finally, when the changes in the left bundle-branch 
were examined histologically in cases of hemiblock (Rossi, 1971; J. Lenègre, 1971, personal communication; Demoulin and Kulbertus, 1972; Rizzon et al., 1975) there was no precise and constant correlation between the pathological and clinical observations.

Aware of these uncertainties, a committee of cardiologists appointed by the American College of Chest Physicians (Hecht et al., 1973), convened to revise nomenclature and concepts of cardiac conduction, tried to discourage the use of the currently popular term 'hemiblock', both on morphological and functional grounds, so far with little success.

The aim of the present study is to re-examine the incidence, type, location, and possible clinicopathological significance of histological changes in the conducting system, particularly in the left bundlebranch, in cases of acute or chronic 'left anterior hemiblock'.

\section{Subjects and methods}

The conducting system of the heart has been studied in 8 subjects with electrocardiographic signs of 'left anterior hemiblock' (the diagnostic criteria are those of Rosenbaum, 1970), alone in 1 case, combined with right bundle-branch block in 7, and with first or second degree AV block in 3. In 6 cases the conduction disturbances were

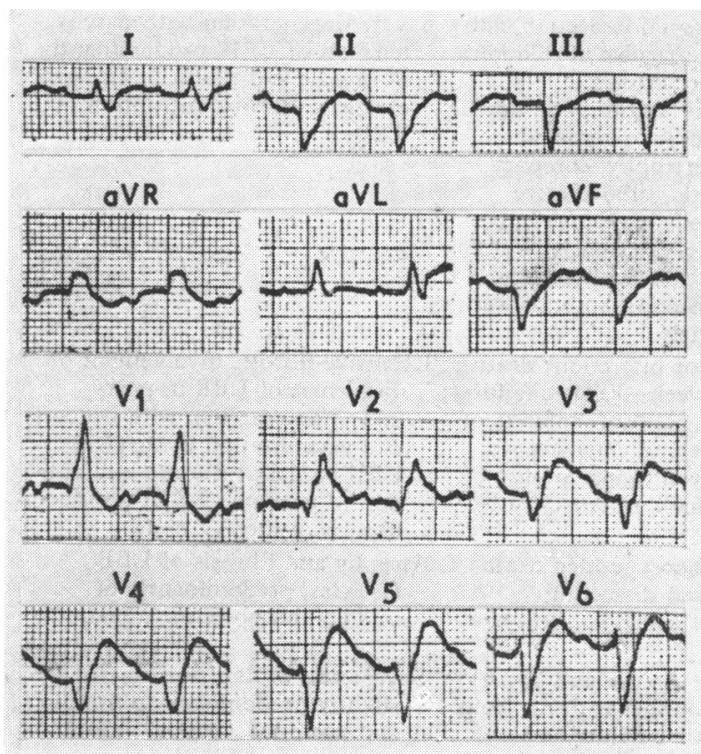

FIG. 1 Case 2. Electrocardiogram showing acute anteroseptal myocardial infarction, with 'left anterior hemiblock', complete right bundle-branch block, and first degree $A V$ block. observed during the course of recent myocardial infarction; in 2 cases they were associated with chronic heart disease. The main clinical and necropsy data are shown in the Table, and an illustrative electrocardiogram is reproduced in Fig. 1.

From each heart, at necropsy, a single block of tissue was removed comprising the ventricular septum (or the upper $3 / 4$ of it), the central fibrous body, and the lowermost part of the atrial septum. The block was fixed in formalin and embedded in paraffin; serial sections were cut at $150 \mu$ intervals along the longitudinal plane of the septa, at right angles to their endocardial surfaces, and were stained with haematoxylin and eosin (H. and E.) or Azan stain to distinguish muscle from collagen. This technique was preferred to that of transverse sectioning of the septum, previously subdivided into several blocks (Demoulin and Kulbertus, 1972), in order to secure the best plane for the observation of the majority of the left bundlebranch fibres, suctioned along their main axis, and to examine the entire conducting system at the same time.

\section{Pathological findings}

'Left anterior hemiblock', in the present cases, was constantly associated with pathological changes in the left bundle-branch. In 6 of the 7 cases with concomitant right bundle-branch block, the right bundle-branch was also severely damaged. No important lesions were observed elsewhere in the conducting system, except for slight fibrosis of the AV node in Case 6.

Impaired blood supply to the myocardium and conducting tissue, by severe atherosclerotic stenosis and/or thrombotic occlusion of major branches of the coronary tree, was found in all hearts except that of Case 7. The left coronary artery was predominantly affected; one case alone had an acute occlusion of the right (Case 4).

The histopathological changes in the left bundlebranch were not discrete and localized, but more widespread, affecting the left side of the ventricular septum and sometimes also the left ventricular walls, particularly when the left bundle-branch was involved in transmural or subendocardial septal infarction.

The lesions of the left bundle-branch were acute and/or subacute, whereas those of the right bundlebranch were always chronic (i.e. fibrotic). Disrupting atrophy and fibrosis of the left bundlebranch in Cases 6, 7, and 8 were not characteristic of Lenègre's or Lev's disease, whose importance in the pathology of hemiblocks has been emphasized 
TABLE Clinical and pathological summary of 8 cases of left anterior hemiblock

\begin{tabular}{|c|c|c|c|c|}
\hline $\begin{array}{l}\text { Case } \\
\text { No. }\end{array}$ & $\begin{array}{c}\text { Age } \\
\text { (y) }\end{array}$ & Sex & Conduction defects & Clinical and necropsy data \\
\hline 1 & 71 & $\mathbf{F}$ & $\mathbf{L A H}+\mathbf{R B B B}$ & $\begin{array}{l}\text { Diabetes, hypertension, acute } \\
\text { anteroseptal infarction, and heart } \\
\text { failure; death after } 1 \text { day } \\
\text { (cardiac arrest); at necropsy, } \\
\text { cardiac hypertrophy, coronary } \\
\text { atherosclerosis, recent thrombotic } \\
\text { occlusion of proximal left } \\
\text { anterior descending coronary } \\
\text { artery, with recent anteroseptal } \\
\text { infarction }\end{array}$ \\
\hline
\end{tabular}
$2 \quad 70 \quad \mathrm{M} \quad \begin{gathered}\mathrm{LAH}+\mathrm{RBBB} \text { and terminal } \\ \text { 1st degree AV block }\end{gathered}$

$\mathrm{LAH}+\mathrm{RBBB}$ and terminal 2nd degree AV block

$\mathrm{LAH}+\mathrm{RBBB}$

$\mathrm{LAH}+\mathrm{RBBB}$ and $1 \mathrm{st}$ degree AV block

$\begin{array}{llll}7 & 26 & \text { M } & \text { LAH } \\ 8 & 71 & \text { M } & \text { LAH }+ \text { RBBB }\end{array}$

Early anteroseptal infarction with recurrent praecordial pain; death after 7 days (left ventricular failure); at necropsy, severe coronary atherosclerosis with severe stenosis of right coronary artery; acute and subacute changes of anteroseptal and posterior infarction

Recent posterior infarction; death after 7 days (ventricular fibrillation); at necropsy, cardiac hypertrophy, coronary atherosclerosis, posteroseptal infarction

Chronic heart disease and hypertension; recent extensive anterior infarction; death from cardiac arrest; at necropsy, anteroseptal and lateral infarction; recent thrombosis of proximal right coronary artery, and diffuse stenosis of left coronary artery

Recent anteroseptal infarction with recurrent ventricular fibrillation; surgical infarctectomy 2 weeks after infarction, and death 16 hours later; at necropsy, cardiac hypertrophy, coronary atherosclerosis, subocclusive thrombosis of proximal left coronary artery; extensive anteroseptal infarction, with sutured surgical incision in anterior wall of left ventricle

Recent posterior infarction; death after three weeks (cardiac failure); at necropsy, subacute infarcts of left ventricle and extensive scarring of ventricular septum; severe coronary atherosclerosis

\footnotetext{
Marfan syndrome; sudden death from ruptured dissecting aneurysm of aorta (confirmed at necropsy)

Chronic heart disease and hypertension; hemiplegia; death from chronic cardiac failure and pulmonary oedema; at necropsy, considerable cardiac hypertrophy and myocardial fibrosis, coronary atherosclerosis
}

Conducting system histopathology

Diffuse oedema, leucocytic infiltration and vacuolar degeneration of lower half of LBB; patchy fibrosis of root and upper posterior radiations

Severe degeneration and small necrotic patches, with leucocytic infiltration and early fibrosis of anterior part of LBB; oedema, vacuolar degeneration, leucocytic infiltration and haemorrhage of middle and posterior radiations; disruptive fibrosis of $\mathrm{RBB}$

Diffuse oedema, leucocytic infiltration and patchy haemorrhage of $\mathrm{LBB}$, predominantly of anterior strands; subendocardial myocardial infarction; fibrosis of RBB

Slight fibrosis of posterior and middle strands with diffuse oedema and scattered leucocytic infiltration of LBB; subendocardial haemorrhage; fibrotic disruption of RBB

Severe degeneration with patchy necrosis of LBB, predominantly of middle and posterior strands; extensive fibrotic disruption of RBB

Extensive fibrotic involvement of distal part of LBB in postinfarction scarring, with oedema and vacuolization of surviving LBB fascicles; fibrotic interruption of proximal RBB; peripheral fibrosis of the AV node

Atrophy and fibrosis of LBB fascicles, predominantly of middle and posterior radiations

Severe and diffuse fibrosis of LBB, slightly predominant in middle and posterior strands, fibrotic interruption of $\mathbf{R B B}$ 


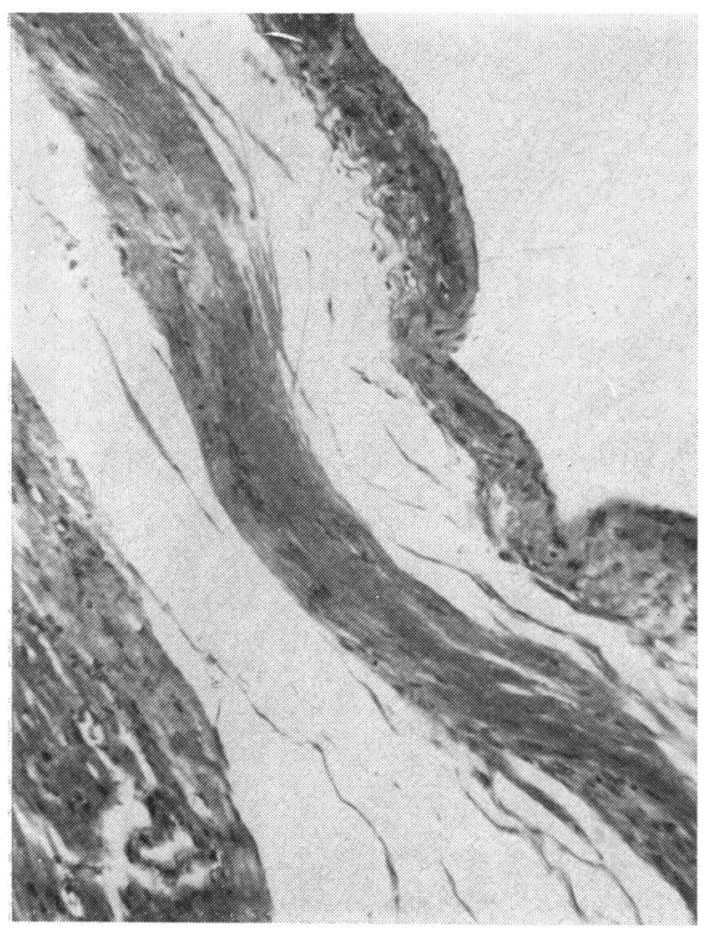

FI G. 2 Case 5. Homogeneous acidophilia with loss of nuclei, from coagulative necrosis of the left bundlebranch in acute myocardial infarction. ( $H$ and $E$ $\times 115$.)

by Rosenbaum et al. (1970). Acute, probably irreversible lesions, namely coagulative necrosis (Fig. 2) and advanced degeneration of myocardial cells, with extreme vacuolization, loss of the myofibrils and of the nucleus (Fig. 3 and 4), were predominant in Case 5, disrupting small fascicles and larger strands of the left bundle-branch. There was extensive damage to the radiations of the left bundle-branch, with replacement fibrosis, in Cases 6, 7, and 8 (Fig. 5, 6, and 7); in Case 6 the left bundle-branch had undergone recent changes alongside older ones (Fig. 7), as a result of recurrent myocardial infarction. Acute probably reversible lesions, such as intra- and extracellular oedema (Fig. 8 and 9), cloudy swelling and vacuolization of myocardial cells with preserved myofibrils and

FIG. 3 Case 5. Gross vacuolization of the fibres of the left bundle-branch, adjacent to acute septal infarction. ( $H$ and $E \times 115$.)

FIG. 4 Case 5. A detail of the severe vacuolization of the left bundle-branch fibres, with loss of myofibrils and of nuclei. ( $H$ and $E \times 450$.)

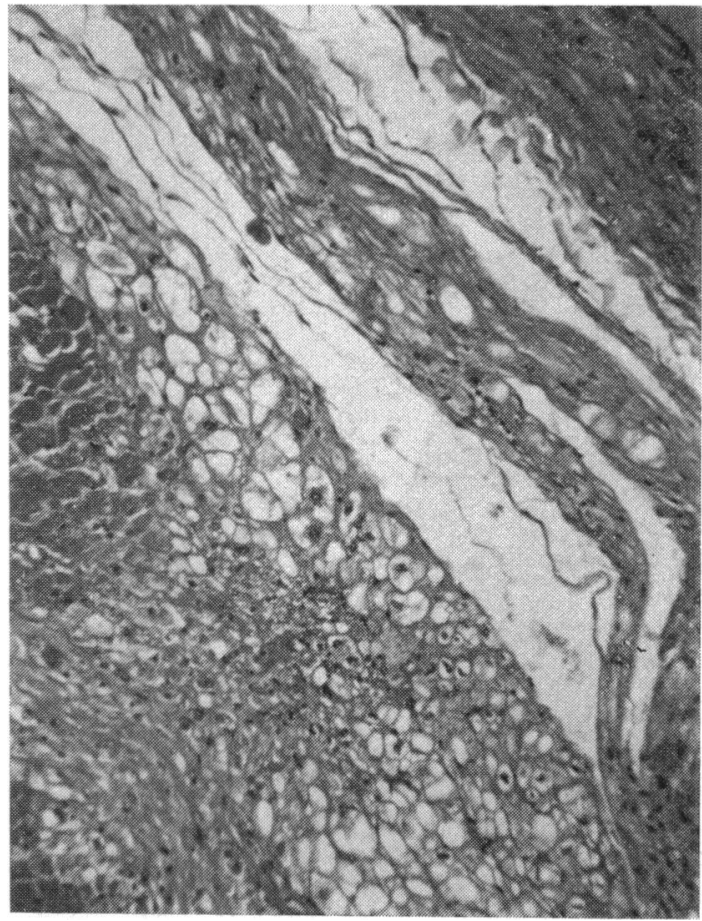

FIG. 3

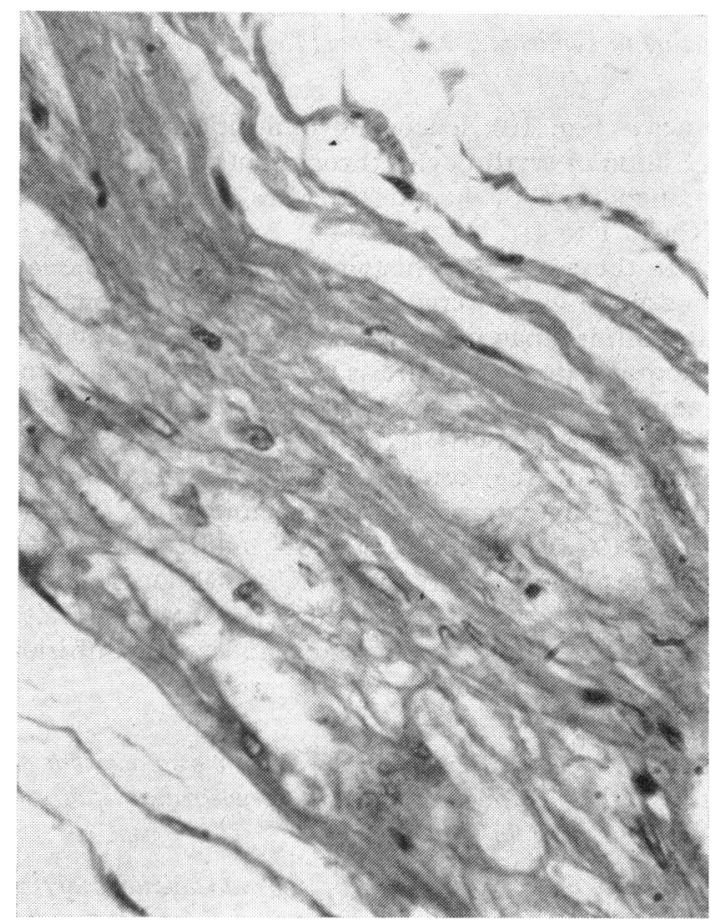

F I G. 4 


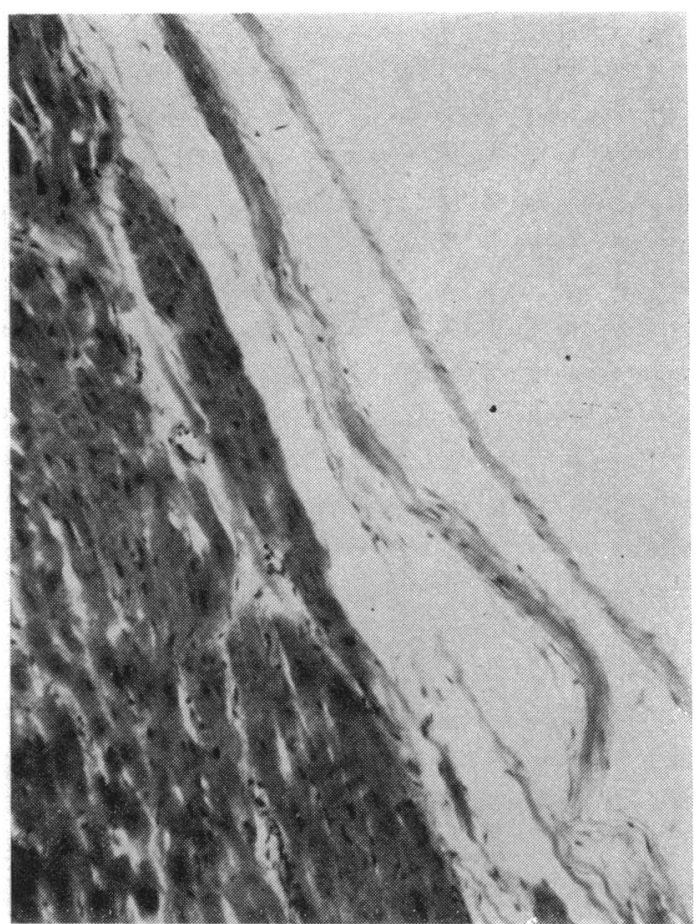

FIG. 5 Case 7. Atrophy and fibrosis of individual fibres of the left bundle-branch, in patient with Marfan syndrome. (Azan $\times 115$.)

nuclei (Fig. 10), leucocytic infiltration, and extravasation of erythrocytes throughout the left bundlebranch (Fig. 8, 9, and 10) were seen in 4 hearts (Cases 1 to 4 ).

In these cases the histological changes in the left bundle-branch were frequently less conspicuous and diffuse than in the adjacent myocardium, which showed extensive necrosis, with the usual accompanying changes of evolving myocardial infarction. This discrepancy is accounted for by a higher resistance of the conducting system than of unspecialized myocardium to ischaemic injury (Hackel et al., 1972; Ekelund et al., 1972). The left bundlebranch, owing to its subendocardial location and closeness to the cavity of the left ventricle, is also likely to be protected by transendocardial diffusion of oxygen.

FIG. 6 Case 8. Advanced sclerotic replacement of the left bundle-branch, and myocardial fibrosis. ( $H$ and $E \times 115$.)

FIG. 7 Case 6. A patch of subendocardial scarring from septal infarction, disrupting the left bundlebranch. ( $H$ and $E \times 115$.)

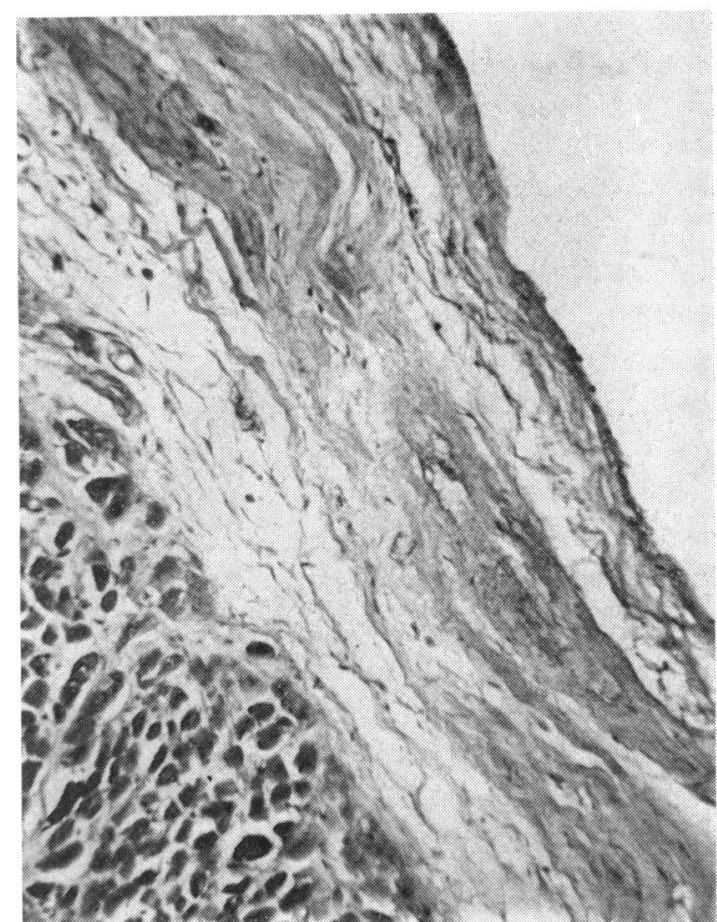

F I G. 6

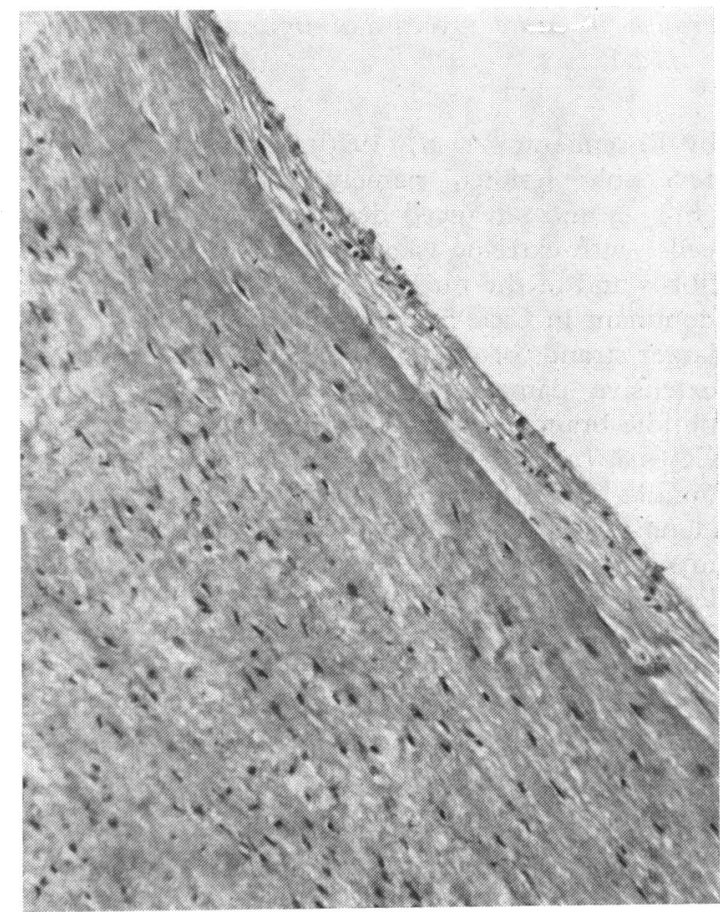

FI G. 7 


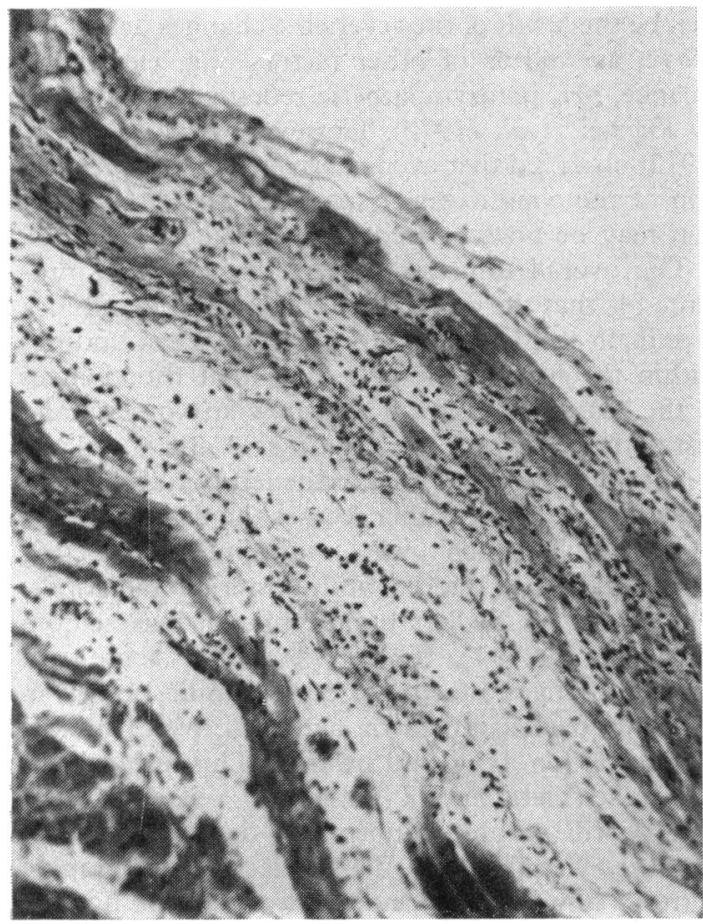

FIG. 8

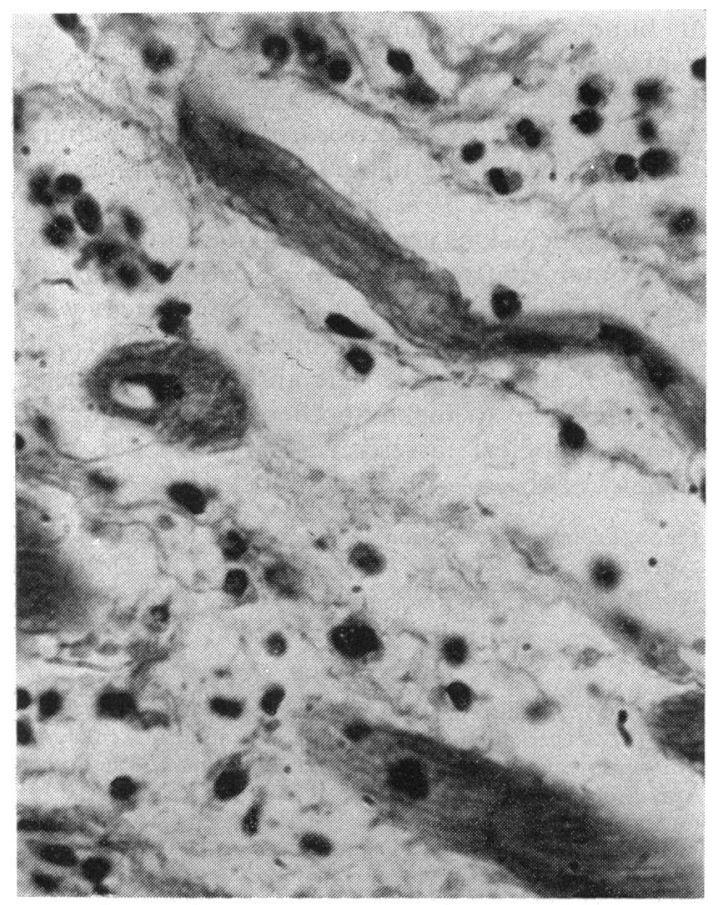

FI G. 9

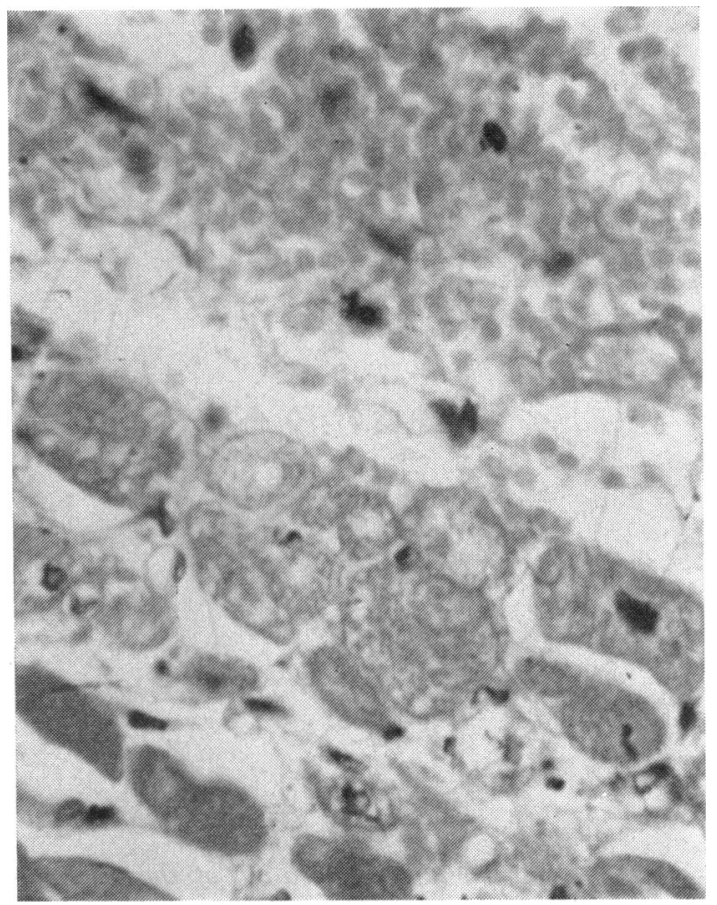

FI G. 10 Case 3. Cloudy swelling and slight vacuolization of fibres of the left bundle-branch, with subendocardial haemorrhage, from acute septal infarction. ( $H$ and $E \times 450$.)

The location of the changes in the left bundlebranch have been illustrated diagrammatically in Fig. 11, in which the approximate site and the predominant type of lesion observed in each heart have been plotted, within a conventional sketch of a trifurcated left bundle-branch. This illustration, despite the intrinsic limitations of such a diagrammatic representation, may be helpful in portraying the salient morphological features in the present group of cases with 'left anterior hemiblock'.

\section{Discussion}

Since attention has been drawn to the prognostic significance of hemiblocks complicating acute myocardial infarction (Atkins et al., 1973; Lichstein, Gupta, and Chadda, 1975; Rizzon et al., 1975),

FIG. 8 Case 1. Subendocardial leucocytic infiltration and oedema, from acute septal infarction involving the left bundle-branch. ( $H$ and $E \times 115$.)

FIG. 9 Case 1. Oedema and leucocytic infiltration of the left bundle-branch in myocardial infarction. ( $H$ and $E \times 450$.) 


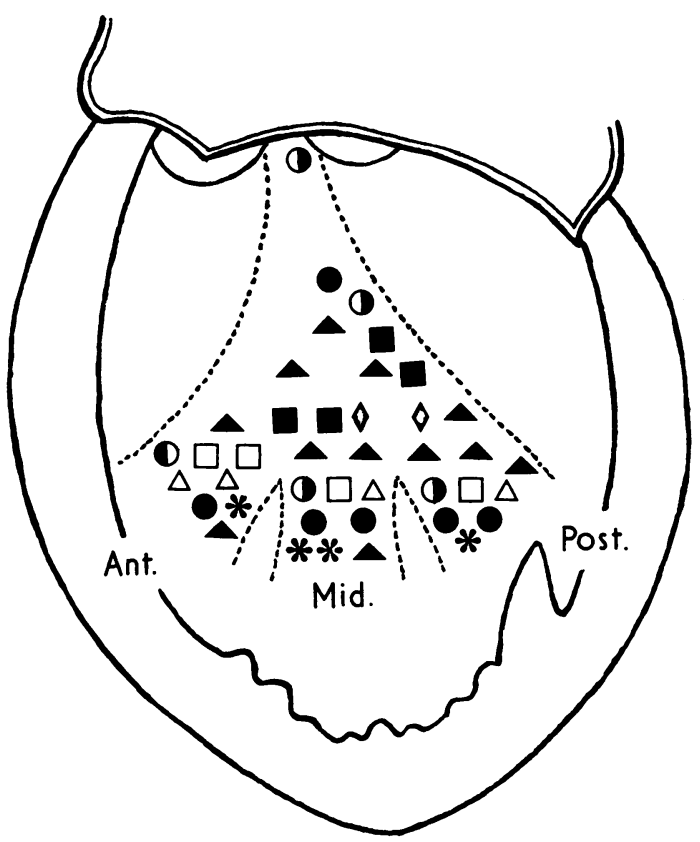

FIG. 11 Diagrammatic illustration of the approximate incidence and distribution of changes in the left bundle-branch, in 8 cases of left anterior hemiblock. Within a conventional outline of the left bundlebranch, the lesions in individual cases are shown by a symbol, as follows: Case 1, 1 ; Case 2, $\square$; Case 3, $\triangle$; Case 4, $\diamond$; Case 5, O; Case 6, *; Case 7, $\square$; Case $8, \Delta$. White symbols denote predominantly reversible changes, and black symbols predominantly irreversible changes (both in Case 1).

serious difficulties have arisen concerning the interpretation of histological signs of damage to the conducting system, in relation to the pathogenesis of the conducting disorder. Rizzon et al. (1975) have recently stressed that anatomical disruption of the conducting pathway by manifestly irreversible lesions, the accepted basis for chronic heart block, including hemiblock (Demoulin and Kulbertus, 1972), is often not seen in cases of myocardial infarction. It has been shown that in the acute stage, the classical easily detected and well-defined 'interruption' of the conducting system is less often seen and less significant than probably reversible and sometimes mild changes, whose extent and functional significance are difficult to determine precisely. There is a need for a working hypothesis to relate histological to electrocardiographic changes. Block after infarction often disappears in patients surviving the early stage; these transient conduction disturbances may well be the result of the reversible changes described above, as well as of other factors (e.g. electrolyte balance, $p \mathrm{H}$, parasympathetic reflexes, etc.) quoted by Hackel et al. (1972). However, Ekelund et al. (1972) observed that even relatively severe degeneration of the conducting tissue in myocardial infarction may be unassociated with conduction defects.

The overall impression from the evidence presented is that the concept of left anterior hemiblock is difficult to reconcile with the histological findings within the left bundle-branch in that the changes in the bundle-branch do not show any precise and distinctive pattern. Only in Cases 2 and 3 did the lesions in the anterior part of the left bundle-branch predominate; in the other 6 cases the damage to the left bundle-branch was widespread, affecting particularly the middle and posterior radiations. The origin of the left bundle-branch was seldom involved (Fig. 11). There were both acute and chronic changes affecting the left bundle-branch in all the hearts examined though these were variable in distribution, type, and severity. This implies that a diseased left bundle-branch is related to the electrocardiographic abnormality described as 'left anterior hemiblock'. This electrocardiographic pattern, however, was not always present nor invariably associated with histological injury confined to the anterior part of the left bundle-branch.

Coexisting cardiac lesions, within and outside the left bundle-branch, notably those involving the septal and parietal walls of the left ventricle, should also be considered in discussing the pathological counterpart of the electrocardiographic pattern which goes under the name of 'left anterior hemiblock' (J. Lenègre, 1971, personal communication).

These conclusions are based on an examination of hearts obtained from a group of patients most of whom had acute lesions, but are in agreement with those of Demoulin and Kulbertus (1972) who studied chronic cases of 'left anterior hemiblock'. It is opportune to make another plea for sounder clinicopathological assessment and proper terminology of the so-called hemiblocks.

I thank Professor P. Rizzon (University of Bari), Professor L. Matturri (University of Milan), and Dr. J. C. Demoulin (the University of Liège) for support.

\section{References}

Atkins, J. M., Leshin, S. J., Blomqvist, G., and Mullins, C. B. (1973). Ventricular conduction blocks and sudden death in acute myocardial infarction. New England fournal of Medicine, 288, 281.

Blondeau, M., and Lenègre, J. (1970). Bloc Atypique de la Branche Droite. Masson, Paris.

Demoulin, J. C., and Kulbertus, H. E. (1972). Histopathological examination of concept of left hemiblock. British Heart fournal, 34, 807. 
Durrer, D., van Dam, R. T., Freud, G. E., Janse, M. J., Meijler, F. L., and Arzbaecher, R. C. (1970). Total excitation of the isolated human heart. Circulation, 41, 899.

Ekelund, L-G., Moberg, A., Olsson, A. G., and Orö, L. (1972). Recent myocardial infarction and the conduction system. A clinico-pathological correlation. British Heart fournal, 34, 774.

Hackel, D. B., Wagner, G., Ratliff, N. B., Cies, A., and Estes, E. H., Jr. (1972). Anatomic studies of the cardiac conducting system in acute myocardial infarction. American Heart fournal, 83, 77.

Harris, R., Siew, S., and Lev, M. (1969). Smoldering myocarditis with intermittent complete A-V block and StokesAdams syndrome. A histopathologic and electrocardiographic study of 'trifascicular' bundle branch block. American fournal of Cardiology, 24, 880.

Hecht, H. H., Kossmann, C. E., Childers, R. W., Lev, M., Rosen, K. M., Pruitt, R. D., Truex, R. C., Uhley, H. N., and Watt, T. B. (1973). Atrioventricular and intraventricular conduction. Revised nomenclature and concepts. American fournal of Cardiology, 31, 232.

Kulbertus, H. (1972). Contribution à l'étude des blocs segmentaires de la branche gauche du faisceau de His et de leurs associations avec le bloc de branche droit. Memoir, Université de Liège.

Lichstein, E., Gupta, P. K., and Chadda, K. D. (1975). Long-term survival of patients with incomplete bundle branch block complicating acute myocardial infarction. British Heart fournal, 37, 924.

Medrano, G. A., De Micheli, A., Brenes, P. C., and SodiPallares, D. (1975). Experimental bases for diagnosis of left bifascicular and trifascicular block. Giornale Italiano di Cardiologia, 5, 8.

Pryor, R., and Blount, S. G. (1966). The clinical significance of true left axis deviation. Left intraventricular blocks. American Heart fournal, 72, 391.
Rizzon, P., Rossi, L., Baissus, C., Demoulin, J. C., and Di Biase, M. (1975). Left posterior hemiblock in acute myocardial infarction. British Heart fournal, 37, 711.

Rosenbaum, M. B. (1970). The hemiblocks: diagnostic criteria and clinical significance. Modern Concepts of Cardiovascular Disease, 39, 141.

Rosenbaum, M. B., Elizari, M. V., and Lazzari, J. O. (1968), Los Hemibloqueos. Paidos, Buenos Aires.

Rosenbaum, M. B., Elizari, M. V., Kretz, A., and Taratuto, A. L. (1970). Anatomical basis of AV conduction disturbances. In Symposium on Cardiac Arrhythmias, Elsinore, p. 147. Ed. by E. Sandøe, E. Flensted-Jensen, and K. H. Olesen. AB Astra, Södertälje, Sweden.

Rossi, L. (1970). Histopathological features of cardiac arrhythmias. In Symposium on Cardiac Arrythmias, Elsinore, pp. 127 and 166. Ed. by E. Sandøe, E. Flensted-Jensen, and K. H. Olesen. AB Astra, Södertälje, Sweden.

Rossi, L. (1971). Sistema di conduzione trifascicolare ed emiblocchi di branca sinistra. Considerazioni anatomiche ed istopatologiche. Giornale Italiano di Cardiologia, 1, 55.

Rossi, L. (1974). Anatomia normale del sistema di conduzione. In Stimolazione Elettrica del Cuore, Fig. 1-1 and Fig. 1-11. Ed. by P. Rossi, C. Ranzi, and F. De Bellis. Piccin, Padua.

Rossi, L. (1975). La diagnosi di blocco bifascicolare o trifascicolare sinistro. Giornale Italiano di Cardiologia, 5, 601 .

Sugiura, M., Okada, R., Hiraoka, K., and Ohkawa, S. (1969). Histological studies on the conduction system in 14 cases of right bundle-branch block associated with left axis deviation. Fapanese Heart fournal, 10, 121.

Requests for reprints to Dr. Lino Rossi, Via Annunciata 23/4, 20121 Milan, Italy. 